East African Medical Journal Vol. 85 No. 5 May 2008

ANATOMICAL VARIATIONS OF THE CAROTID ARTERIES IN ADULT KENYANS

D. Anangwe, BSc (Anat), H. Saidi, BSc (Anat), MBChB, MMed, FCS, Senior Lecturer, J. Ogeng'o, BSc. (Anat), MBChB and K.O. Awori, MBChB, MMed, Department of Human Anatomy, College of Health Sciences, University of Nairobi, P.O. Box 30197-00100, Nairobi, Kenya

Request for reprints to: Dr. H. Saidi, Department of Human Anatomy, College of Health Sciences, University of Nairobi, P.O. Box 30197- 00100, Nairobi, Kenya

\title{
ANATOMICAL VARIATIONS OF THE CAROTID ARTERIES IN ADULT KENYANS
}

\author{
D. ANANGWE, H. SAIDI, J. OGENG'O and K.O. AWORI
}

\begin{abstract}
Objective: To describe the topography and anatomical variations of the carotid arteries among Kenyans.

Design: A descriptive cross-sectional study.

Setting: Department of Human Anatomy, University of Nairobi.

Subjects: Eighty carotid arteries of forty cadavers were dissected.

Results: The bifurcation of the commonest carotid artery was high (above the reference points) in $63.8 \%$ of vessels and the external carotid was antero-lateral to the internal carotid artery in $30 \%$ of the vessels. A linguo-facial trunk was the most common variation of the external carotid artery. The origin of the right common carotid artery was high and low in $10 \%$ and $2.6 \%$ of vessels respectively.

Conclusion: The carotid arteries show important variability and thus emphasise caution for clinicians during surgical procedures in the neck.
\end{abstract}

\section{INTRODUCTION}

The relations and patterns of branching of the extra-cranial carotid arteries show inter-population variations. The external carotid artery may be positioned anterolateral to the internal carotid in up to half of necks $(1,2)$. Cases of common linguothyroid, linguofacial and occipito-auricular trunks have been reported (3). In reference to what is considered a normal level of carotid bifurcation (C34 intervertebral disc), there are usually more cases of high as compared to low bifurcations (4).

Variations in the branching patterns may increase the risk of accidental vascular accidents during surgical procedures in the neck. Stover et al (5) have associated high bifurcations with higher incidences of vascular trauma following penetrating injuries to the neck. Further, aberrations may also be responsible for angiographic misinterpretation (6).
There are no publications to our knowledge on variations of carotid arteries in Africans. The aim of this study was to describe the anatomical variations of the carotid arteries among Kenyans.

\section{MATERIALS AND METHODS}

Cadavers used for dissection were availed from the Department of Human Anatomy, University of Nairobi. Eighty carotid vessels (40 left, 40 right) were dissected for the purpose of data collection. The cadaveric specimens that were dry and difficult to dissect and those that were macerated by students before data collection were excluded from the study.

Skin incisions from, the chin to the suprasternal notch and along the lower border of the mandible were made. Skin flaps were reflected for exposure of the anterior triangle of the neck. The bifurcation of the common carotid artery was then exposed as 
were the branches of the external carotid artery. The point of bifurcation of the brachiocephalic trunk was determined after removal of the insertions of the sternocleidomastoid muscle on the clavicle and the sternum and disarticulation of the sternoclavicular joint. The level of bifurcation of the common carotid artery, relation of the external carotid artery to internal carotid artery, branching pattern of the external carotid artery and level of origin of the right common carotid artery were observed and recorded. Variant patterns were those that did not fit the classical description of the branching pattern of the external carotid artery.

High levels of bifurcation were considered to be above the C3-4 inter-vertebral junction, and low bifurcations below it. The upper border of thyroid cartilage was the anterior landmark for the C3-4 junction. High or low levels of origin of the right common carotid artery were defined in relation to the level of the sternoclavicular joint.

Data obtained were managed using the SPSS version 12.0 statistical software. The results are summarised in the form of frequencies and presented in the form of frequency table and photographs.

\section{RESULTS}

Level of bifurcation of the common carotid artery: Fifty one $(63.8 \%$ ) bifurcations were high among which the most common levels of bifurcation was at the level of C3 vertebral body (38.8\%). The most common low bifurcation was at C4 vertebra level (7.5\%) (Table 1 and Figure 1). There were no statistically significant side-to-side differences in level of bifurcation.

Table 1

Frequency of levels of bifurcation of the common carotid artery

\begin{tabular}{clcc}
\hline Level of bifurcation & No. & $(\%)$ \\
\hline \multirow{2}{*}{ High } & C2 & 10 & 12.5 \\
& C2-3 & 10 & 12.5 \\
& C3 & 31 & 38.8 \\
Normal & C3/4 & 18 & 22.5 \\
Low & C4 & 6 & 7.5 \\
& C5 & 2 & 2.5 \\
& C6/7 & 3 & 3.75 \\
\hline
\end{tabular}

Figure 1

High (1 $a)$ and low (1 b) bifurcation levels of the common carotid artery. The reference level in these images is the thyroid cartilage (Th), specifically the upper border of the thyroid cartilage lamina (ThLUB)
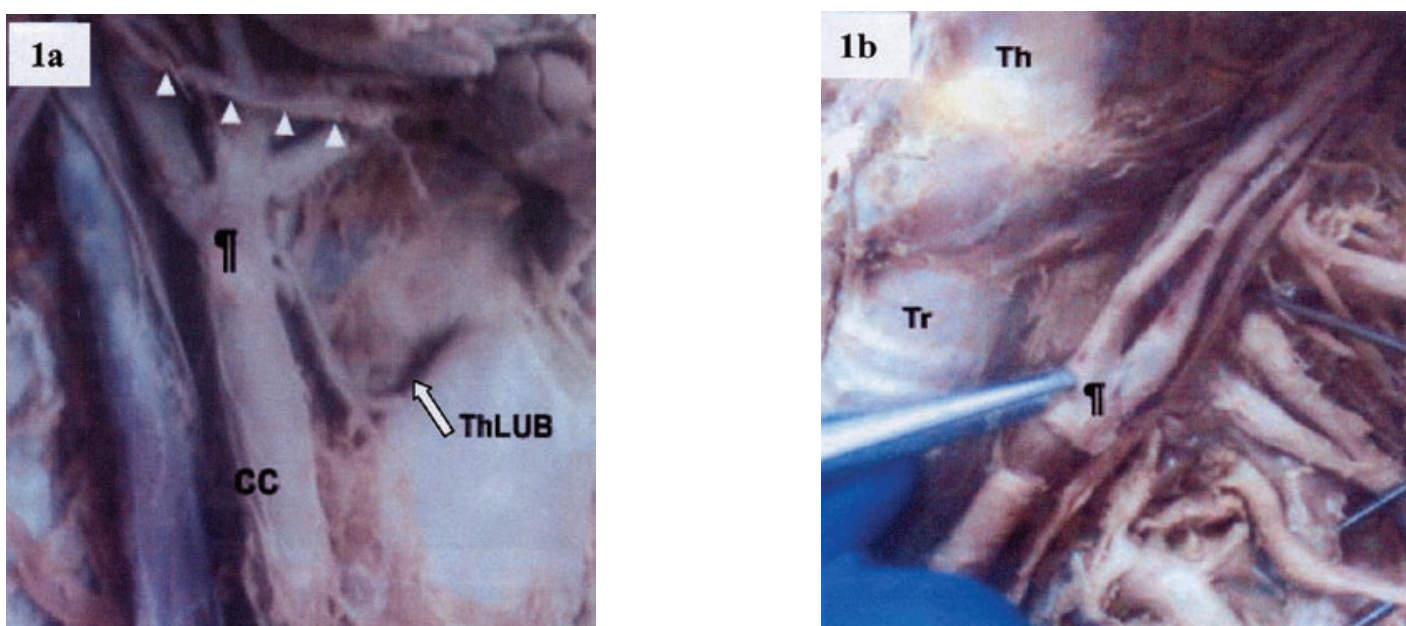

$\operatorname{Tr}=$ Trachea; $\mathbb{I}=$ Carotid Bifurcation; Th = Thyroid cartilage $; C C=$ Common Carotid artery; Hypoglossal nerve $=$ white arrow heads; ThLUB = Thyroid lamina upper border 
Figure 2

Branching pattern of the external carotid artery;- $2 \boldsymbol{a}$ - Linguofacial trunk, $\mathbf{2} \boldsymbol{b}$ - Separate laryngeal artery from common carotid artery, $2 c$ - Absent occipital artery
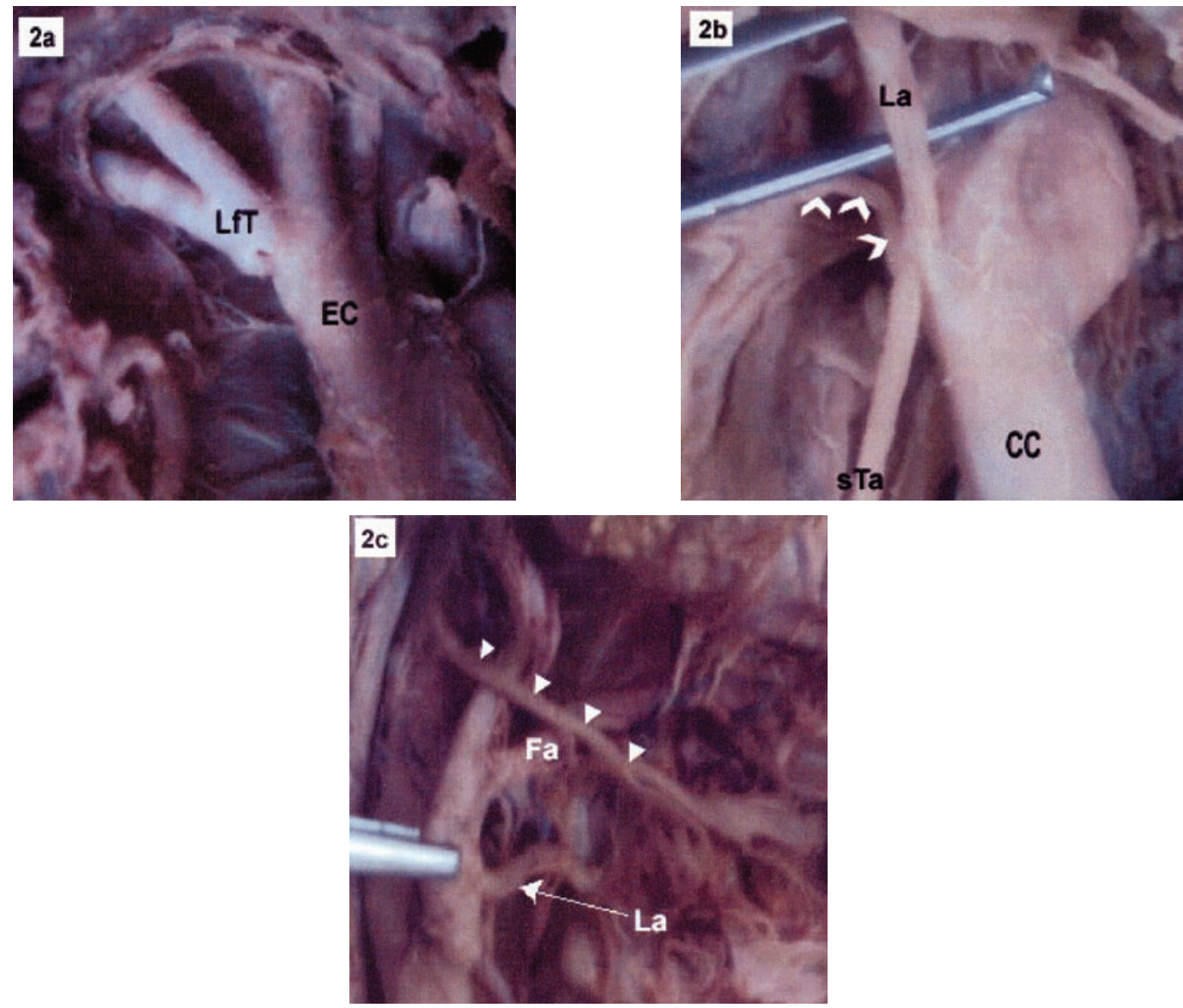

$L f T=$ Linguofacial trunk, EC = External carotid, La = Laryngeal artery, white arrow heads (figure $2 b$ ) - Separate internal laryngeal artery, sTa $=$ Superior thyroid artery, CC = Common carotid artery, Fa = Facial artery, white arrow heads = Hypoglossal nerve

Relation and pattern of branching: The normal relation of external carotid artery (anteromedial) to internal carotid artery was seen in $56(70 \%)$ cases. Variant pattern of branching of the external carotid was observed in seven (9\%) of the dissected vessels (Figure 2). The side differences were not statistically significant.

Of the variant branching patterns, the linguo-facial trunk (Figure 2a) was the most common (7\%) while there was one case of separate branching of the internal laryngeal from the external carotid artery (Figure 2b) and one case of absent occipital artery (Figure 2c).

Level of origin of the right common carotid: Of all the right common carotid arteries dissected, 10\% had an origin above sternoclavicular joint (Figure 3) while $2.6 \%$ had an origin below the joint. Majority (87.5\%) had an origin behind the sternoclavicular joint.
Figure 3

High bifurcation of the brachiocephalic trunk, above the sternoclavicular joint

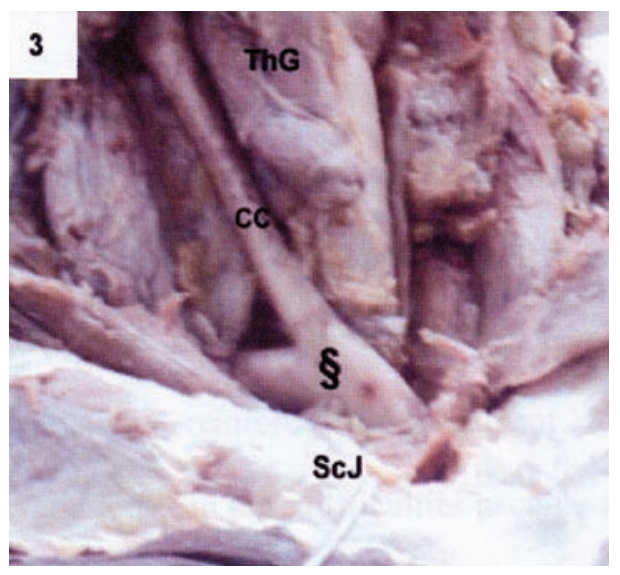

Th $G=$ Thyroid gland $\S=$ Brachiocephalic bifurcation; ScJ = Sternoclavicular joint; $C C=$ Common Carotid artery 


\section{DISCUSSION}

The present study has recorded a frequency of $38.8 \%$ for common carotid bifurcation at the $\mathrm{C} 3$ vertebra and $22.5 \%$ at the C3-4 intervertebral disc level. Terminations higher than C3/C3-4 level were found in 25\% of vessels. Earlier gross anatomical studies and those examining angiographs have indicated variable incidence for C3/ C3-4 bifurcation levels (4) foetuses, the incidence of C3 bifurcation was noted to be $55 \%$ by Zumre et al (4) while the angiographic study by Hayashi et al (3) found C3 termination in 100\% adult carotids. Among adult Japanese a C3 termination occurs in $57.5 \%$ of carotid vessels (2). Our results on side symmetry in the pattern of bifurcation is also at variance with some earlier reports. In the angiographic report by Smith and Larsen (7), the left carotid bifurcation was higher than the right in $50 \%$ of the cases and the right bifurcation higher than left in $22 \%$ of the cases (7). Such accounts pose clinical challenges as they may predispose to angiographic data misinterpretation (4) and surgical complications (6). A high common carotid is at a higher risk of impingement by intra-articular screws during procedures on cervical vertebrae (8).

This study reports a reversal of relationship between the internal and the external carotid arteries in $30 \%$ cases. This prevalence is much higher than the $13 \%$ reported by Trigaux et al (1) amongst Belgians. In a different European population, Kaseff (9) has recorded an incidence of $37 \%$. Such variations reinforce the argument for population-specific data as anatomical variations can pose difficulties during procedures. To limit angiographic mishaps, proposals have been made to use both lateral and anteroposterior views during cervical angiography (9) with CT angiography remaining most efficacious (10).

Variations in the level of origin of the common carotid artery are reported as part of the abnormalities of the supra-aortic trunks (5). Higher levels of origin are associated with higher incidences of penetrating vascular injuries (5). The branching pattern of the external carotid artery was normal in the majority $(91.2 \%)$ of vessels in the current study. The linguofacial trunks, external carotid origin of the internal laryngeal artery and the absence of the occipital artery add to the body of literature depicting the variation of the external carotid. Tubbs et al (11) have reported an absence of the occipital artery at its normal origin but was a continuation of the ascending cervical artery. In the series by Zumre et al (4), linguo-facial, thyrolingual and thyro-linguofacial trunks were recorded in $20 \%, 2.5 \%$ and $2.5 \%$ of 40 Turkish carotid arteries respectively.

In conclusion, the anatomical variability demonstrated for the carotid arteries in this small sample of adult African Kenyans is high and indicates caution during surgical procedures involving the anterior triangle of the neck.

\section{REFERENCES}

1. Trigaux, J.P., Delchambre, F. and Van Beers, B. Anatomical variations of the carotid bifurcation: implications for digital subtraction angiography and ultrasonography. Brit. J. Radiol. 1990; 63: 181-185.

2. Ito, H., Mataga, I., Kageyama, I., et al. Clinical anatomy in the neck region-the position of external and internal carotid arteries may be reversed. Okajimas Folia Anat. Jpn. 2006; 82: 157-167.

3. Hayashi, N., Hori, E., Ohtani, Y., et al. Surgical anatomy of the cervical carotid artery for carotid endarterectomy. Neurol. Med. Chir. (Tokyo). 2005; 45: 25-29.

4. Zumre, O., Salbacak, A., Cicekcibasi, A.E., et al. Investigation of the bifurcation level of the common carotid artery and variations of the branches of the external carotid artery in human fetuses. Ann. Anat. 2005; 187: 361-369.

5. Stover, S., Holtzman, R.B., Lottenberg, L., et al. Blunt innominate artery injury. Amer. Surg. 2001; 67: 757-759.

6. Schulz, U.G.R. and Rothwell, P.M. Sex differences in carotid bifurcation anatomy and the distribution of atherosclerotic plaque. Stroke. 2001; 32: 1525.

7. Smith, D. and Larsen, J. On the symmetry and asymmetry of the bifurcation of the common carotid artery. A study of bilateral carotid angiograms in 100 adults. Neuroradiol. 1979; 17: 245-247.

8. Currier, B.L., Todd, L.T., Maus, T.P., et al. Anatomic relationship of the internal carotid artery to the $\mathrm{Cl}$ vertebra: A case report of cervical reconstruction for chordoma and pilot study to assess the risk of screw fixation of the atlas. Spine. 2003; 28: E461-E467.

9. Kaseff, L.G. Positional variations of the common carotid artery bifurcation: implications for digital subtraction angiography. Radiol. 1982; 145: 377-378.

10. Link, J., Brossmann, J., Penselin, V., et al. Common carotid artery bifurcation: Preliminary results of CT angiography and color-coded duplex sonography compared with digital subtraction angiography. Amer. J. Roentgenol. 1997; 168: 361-365.

11. Tubbs, R.S., Salter, G. and Qakes, W.J. Continuation of the ascending cervical artery as the occipital artery in man. Anat. Sci. Int. 2004; 79: 43-45. 